\title{
EVALUATION OF HORIZONTAL CURVE RADIUS EFFECT ON DRIVING SPEED IN TWO LANE RURAL ROAD. PILOT STUDY
}

\author{
MINDAUGAS ŠEPORAITIS ${ }^{*}$, VIKTORAS VOROBJOVAS ${ }^{2}$, \\ AUDRIUS VAITKUS ${ }^{3}$
${ }^{1,2}$ Dept of Roads, Vilnius Gediminas Technical University, Vilnius, Lithuania ${ }^{3}$ Road Research Institute, Vilnius Gediminas Technical University, Vilnius, Lithuania

Received 19 May 2020; accepted 13 July 2020

\begin{abstract}
This paper presents a case study of driving speed at horizontal curves in the regional road. The literature review of operating speed at horizontal curves in regional roads expresses the difference between design speed and driving speed. Driving speed was measured in ten horizontal curves on regional road No. 2610. Collected data was compared to the design speed, various design standards, and Operating Speed Prediction Models for traffic in low-volume roads. Based on result analysis, was proposed initial adjusted minimum radius of the horizontal curve based on operating speed. It is justified that proposed corrections based on operating speed ensure a credible speed limit effect on road safety. The performed experiment showed different tendencies comparing measured driving speed with permitted and design speeds. It was determined that dependent on specific curved section drivers tend to exceed posted
\end{abstract}

* Corresponding author. E-mail: mindaugas.seporaitis@vgtu.lt

Mindaugas ŠEPORAITIS (ORCID ID 0000-0002-0619-9802)

Viktoras VOROBJOVAS (ORCID ID 0000-0001-9420-0668)

Audrius VAITKUS (ORCID ID 0000-0001-5103-9747)

Copyright (C) 2020 The Author(s). Published by RTU Press

This is an Open Access article distributed under the terms of the Creative Commons Attribution License (http://creativecommons.org/licenses/by/4.0/), which permits unrestricted use,

distribution, and reproduction in any medium, provided the original author and source are credited. 
speed limit from $17 \%$ to $98 \%$ of cases, and from $41 \%$ to $100 \%$ - the design speed in the horizontal curve. This research led to identifying the limitations of experimental research methodology. These limitations are related to experimental Site selection with different combinations of alignment elements, traffic, and accident data. A pilot study showed significant results and gave essential insights into the full-scale research plan. The results are expected to benefit both other researchers and the organisations responsible for the development and implementation of normative technical documents for road design.

Keywords: design speed $\left(V_{d}\right)$, horizontal curve, low-volume road, operating speed $\left(V_{85}\right)$, regional road.

\section{Introduction}

In most countries, design guidelines of the road alignment include permissible speed $\left(V_{\text {perm }}\right)$, design speed $\left(V_{d}\right)$ and $85^{\text {th }}$-percentile speed $\left(V_{85}\right)$. The permissible speed is defined by general regulation or local maximum speed limit. Individual alignment design elements are unrelated to $V_{\text {perm }}$. For road safety reasons, the goal is that $V_{d}$ of the horizontal curve always be no lower than $V_{\text {perm }}$ - posted speed. Limiting and standard values for most of the design elements are determined conforming to the $V_{d}$ : maximum tangent lengths, minimum radii of the horizontal curve, minimum parameters of clothoids, maximum longitudinal grades and vertical curves. Constant $V_{d}$ must be applied consistently on longer sections or at least on longer connected roadway sections (Lamm, Psarianos, \& Mailaender, 1999). It is desirable that the driving speed of a large proportion of drivers be lower than the $V_{d}$ (AASHTO, 2018). Significant differences in speed results in an increase in the frequency with which vehicle drivers pass one another, increasing the number of opportunities for multivehicle crashes. Vehicles travelling the same speed in the same direction withholds overtaking one another. Therefore, it is impossible to collide if the same speed is maintained.

As reported by the Elliott, Dawson, \& Edwards (2006) research report, the relationship between speed variance and safety were not entirely conclusive. Moreover, it is incompletely clear what the relationship exactly means. In most studies, speed differences reflect the range in speeds over 24 hours of measurements (Elliott, Dawson, \& Edwards, 2006). The measured speed differences must include the variation between peak and off-peak periods, traffic volume and indefinitely speed between vehicles at a particular moment.

Elvik (2014) reviewed thirteen studies, which evaluated the effects of speed variance on crash rates, based on loop detector data. Although almost all these studies found that a large variance in speed increased
Evaluation

of Horizontal Curve

Radius Effect

on Driving Speed

in Two Lane Rural

Road. Pilot Study 
the risk of crashes, the numerical estimates of the effect varied greatly. It is nevertheless clear that increased driving speed variance increases the risk of crashes. However, most of these crashes are probably propertydamage-only crashes. Dense traffic characterised by frequent and sudden changes in speed is associated with an exceptionally high risk of crashes (Elliott, Dawson, \& Edwards, 2006).

As widely characterised in literature, the drivers must understand what speeds they are expected to drive. Road design should be selfexplaining, reflecting the speed limit and guiding road users in choosing the right speed. So-called sustainable safety concept aims at preventing severe road crashes and were impossible - limiting their consequences (SWOV, 2013).

There is global voluntary performance Target No. 6 for Road Safety Risk Factors and Service Delivery Mechanisms there is stated: "By 2030, halve the proportion of vehicles travelling over the posted speed limit and achieve a reduction in speed-related injuries and fatalities" (World Health Organization, 2018).

The rational speed limit is a safe one, which most people consider appropriate, that protect the public, and can be enforced. Artificially low-speed limit leads to poor compliance as well as significant variations in speed within the traffic flow. Increased speed variance creates more conflicts and passing manoeuvres that can lead to more crashes. In road sections in rural areas where crash risk is typically lower, many experts recommend posting the speed limit at the $10 \mathrm{~km} / \mathrm{h}$ multiple closest to the $85^{\text {th }}$ percentile speed $\left(V_{85}\right.$ the speed at which no more than $85 \%$ of drivers are observed operating their vehicles during free-flow conditions). Most experts agree that in road section with a high crash rate, a detailed crash analysis needs to be conducted to identify the contributing factors for all crashes (Srinivasan, Parker, Harkey, Tharpe, \& Sumner, 2006).

The fact that the speed limit is set conforming to road design guidelines based on traffic safety considerations and neglected the road users natural speed adaptation to the roadway contribute to the high rates of speed violations (Vadeby \& Forsman, 2014). The debate raises whether the $V_{d}$ specified in the road design guidelines (the minimum radius for a $V_{d}$ ) is indeed overestimated and doubtfully based on traffic safety. In a comparison done by Organization for Economic Cooperation and Development (European Conference of Ministers..., 2006), typically $40 \%-50 \%$ of drivers tend to exceed the posted speed limit (European Conference of Ministers..., 2006). It is shown in further research that drivers prefer to drive $4-5 \mathrm{~km} / \mathrm{h}$ faster than the speed limit they consider as safe (Goldenbeld \& van Schagen, 2007).

An accepted principle is that every $1 \%$ increase in mean speed produces a $4 \%$ increase in the fatal crash risk and a 3\% increase in the 
fatal crash risk. Also, a 5\% reduction in average speed can reduce the number of fatalities by 30\% (World Health Organization, 2018).

The speed limit rarely is credible when operating speed $\left(V_{85}\right)$ is higher than the posted speed limit. A credible speed limit is defined as the driving speed that most road users consider to be reasonable, for that particular road layout (Aarts, van Nes, Donkers, \& van der Heijden, 2010). Drivers tend to better comply with the speed limit when speed limits are more credible (Goldenbeld \& van Schagen, 2007).

The design speed must never be lower the permissible speed. It is unreasonable to have a speed limit that is much lower the $V_{d}$ of a road. This incompatibility damages the credibility of a speed limit. Furthermore, the $V_{d}$ must be consistent over a longer stretch of road. A substantial reduction of $V_{d}$ at a particular Site must be supported by more than just a sign with the reduced speed limit (European Commission, 2015).

The German Guide has an officially used concept of $V_{85}$ for the Geometric Design of Highways since 1973. The regulation used the $V_{85}$ as an evaluation parameter for alignment consistency. Also, subsequent regulations (1984 and 1995) provided different diagrams for new and existing roads to estimate the $V_{85}$ as a function of road characteristics. The road design guidelines of many other countries provide Operating Speed Prediction Models (OSPMs) (for example, France, Greece, and Australia) or provide a design process, which is associated to the $85^{\text {th }}$ percentile speed (for example, the United Kingdom). These road design guidelines usually contain specific evaluations to check the consistency of the alignment or sight distance using $V_{85}$.

Moreover, in these countries, the $V_{85}$ is also used for determining permissible speed. On the contrary, there are several countries (for example, Lithuania, Italy, Slovenia, and Spain) whose road design guidelines conceal $V_{85}$ concept. In these cases, the design process generally uses a $V_{d}$, which is unrelated to an experimental survey but is based on theoretical considerations (Dimaiuta, Donnell, Himes, \& Porter, 2011). The need for OSPMs is particularly significant for the evaluation of existing roadway conditions to aid in the selection and identification of valid and defensible roadway improvements.

Operating speed considers the expected actual speed behaviour and usually is expressed as $V_{85}$. The operating speed is used for safety evaluation process conforming to Safety Criteria I to III and also it is used to determine inconsistencies between $V_{d}$ in design regulations and actual drivers behaviour (American Association of State..., 2018; Lamm, Beck, Ruscher, Mailänder, Cafiso, \& La Cava, 2007). Among the different existing measures for design consistency evaluation, the $V_{85}$ approach appreciable as the most efficient and quantified measure. 
Operating speed backgrounds should be part of every modern road design guideline when striving for proper curvilinear alignment, and a more consistent and safer road characteristic (Lamm, Beck, Ruscher, Mailänder, Cafiso, \& La Cava, 2007).

The development of OSPMs on rural roads in Lithuania is still at its early stage. The research described in this paper aims at taking the development of OSPM in Lithuania one step further. The focus is, therefore on the practice of Lithuania, where relatively small horizontal curves in rural roads are of great concern, and their use is unrelated to experimental driving speed studies. A pilot study has been carried out to make sure there is a need to refine the $V_{85}$ background in Lithuania. How normative limitations to $V_{d}$ and the minimum radius of the horizontal curve is corresponding to $V_{85}$ on rural two-lane roads or how the speed selected by the driver differs from the $V_{d}$.

The paper aims at the revision of other countries road design guidelines and OSPMs, describing a basic framework for the development of $V_{85}$ background in horizontal curves in practice. The following section describes the experiment background for comparable results. Subsequently, field results are analysed, $V_{85}$ calculated and discussed.

Methodology and fundamentals used for calculating radius of the horizontal curve are widely discussed by other researches (American Association of State..., 2018; DHV Environment and Transportation, 2005; Gintalas, 2010; Lamm, Psarianos, \& Mailaender, 1999). The methodology suggested by World Bank considers that the minimum radius is related to the applied superelevation of the horizontal curve. Also, specific skid resistance factors are used at various design speed. The Eq. (1) is used to calculate the radius of the horizontal curve:

$$
R_{h} \geq \frac{V_{d}^{2}}{127\left(f_{z}+\frac{i}{100}\right)},
$$

where $R_{h}$ - the radius of the horizontal curve, m; $V_{d}$ - design speed, $\mathrm{km} / \mathrm{h} ; f_{z}$ - skid resistance factor; $i$ - superelevation.

The basic formula for vehicle operation on a horizontal curve developed from the laws of mechanics is shown by Eq. (1).

The equation, as mentioned above, is used in various countries but with different values of skid resistance factors. The values used for skid resistance, mainly vary with them $V_{d}$ within different countries worldwide.

Many countries use $V_{d}$, which is manually defined or tabular parameter with interrupted functionality, dependent on the road category and importance and is used for defining boundary design parameters. 


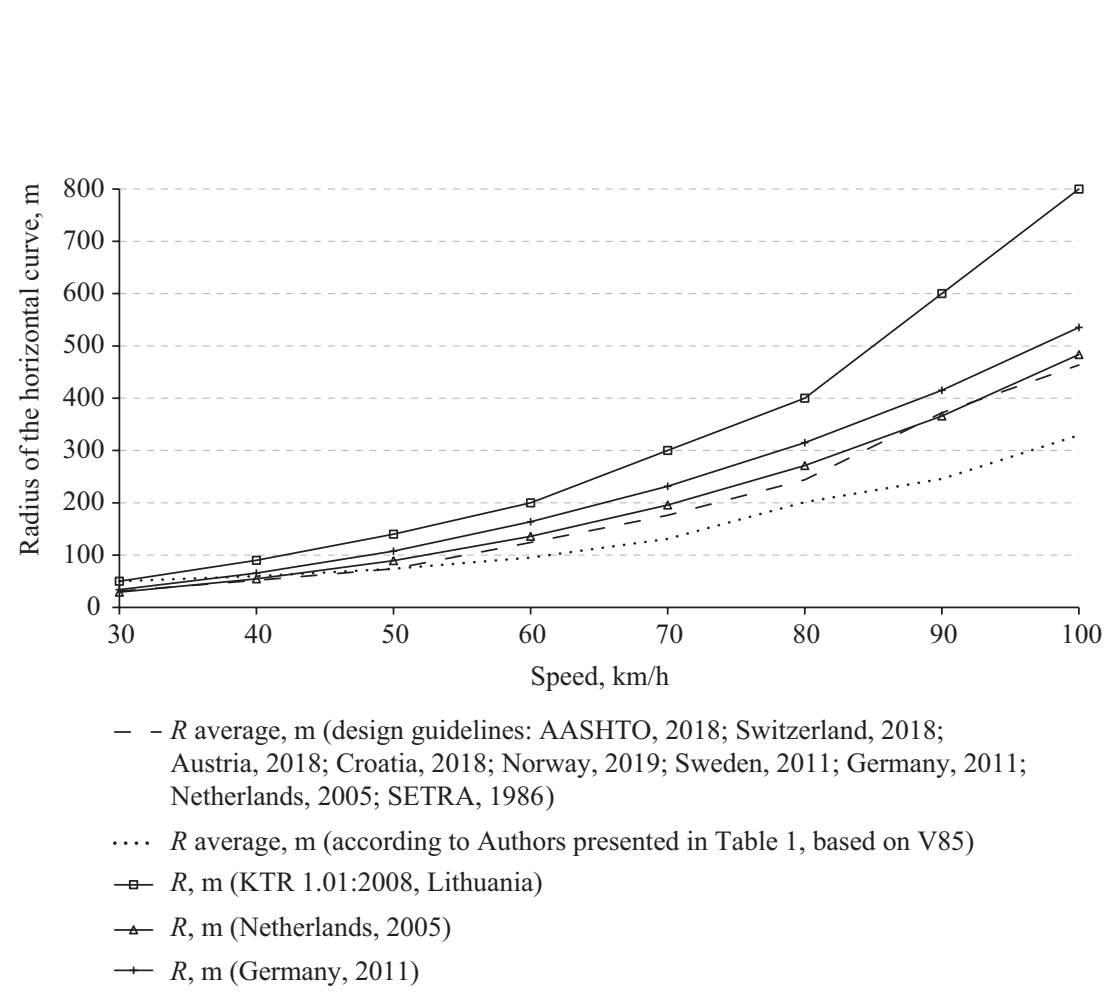

Figure 1. Average of minimum radius of horizontal curve at certain design speed in various countries and average of developed operating speed prediction models by various authors.

Design speed in Lithuania strictly depends on the road category, as stated in the available road design guidelines. However, there is inconsistency with Road Traffic Rules. The design speed of the road category V with asphalt pavement is $70 \mathrm{~km} / \mathrm{h}$. However, the permissible speed by the Road Traffic Rules is $90 \mathrm{~km} / \mathrm{h}$. Under widely in various countries developed speed predicting models and $V_{d}$, minimum design radius of the horizontal curve in Lithuania is overestimated. It is unrelated to defined driving speed measurements (Figure 1). Either there is no term $V_{85}$ or operating speed used in available Lithuanian road design guidelines.

Figure 1 shows a significant difference between radius of the horizontal curve and $V_{d}$ in Lithuanian regulations and leading countries (Germany, Netherlands) with high traffic safety standards. There were calculated average $V_{d}$ and $V_{85}$ for fixed radius of the horizontal curve $(R)$ as stated in national standards or description provided in published articles (American Association of State..., 2018; Abbas, Adnan, \& Endut, 2011; Camacho-Torregrosa, Pérez-Zuriaga, Campoy-Ungría, \& GarcíaGarcía, 2013; Castro, Pardillo-Mayora, \& Jurado, 2013; Dilling, 1973; Kanellaidis, Golias, \& Efstathiadis, 1990). 


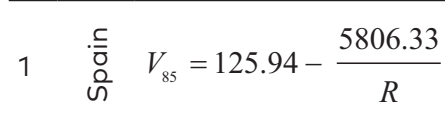

$\begin{array}{rll}2 . \frac{5}{0} & V_{85}=102.048-\frac{3990.26}{R}, \\ \text { जे } & \text { when } 70 \mathrm{~m}<R \leq 400 \mathrm{~m}\end{array}$

\begin{tabular}{ll}
$V_{851}$ & Castro, Pardillo- \\
horizontal curve radius $(R)$ & Mayora, \& Jurado, \\
based on 42 horizontal curves & 2013 \\
\hline$V_{851}$ & Camacho-Tor- \\
horizontal curve radius $(R)$ & regrosa, Pérez- \\
based on 62 segments & Zuriaga, Campoy- \\
& Ungría, \\
& $\&$ García-García, \\
& 2013
\end{tabular}

$V_{85}$

Dilling, 1973

horizontal curve radius $(R)$

$V_{\text {avg }}$ - average driving speed

on a horizontal curve,

$b$ - lane width,

$C C R$ - curvature change rate

of the roadway section

$V_{85}$, radius $(R)$

Kanellaidis, Golias,

\& Efstathiadis,

1990

$V_{85 M C}$ at the middle horizontal

Abbas, Adnan,

curve,

\& Endut, 2011

horizontal curve radius $(R)$,

$V_{85 A T}$ at approach tangent

$\begin{array}{ll}\begin{array}{l}V_{851} \\ \text { horizontal curve radius }(R)\end{array} & \begin{array}{l}\text { Castro, Pardillo- } \\ \text { Mayora, \& Jurado, } \\ 2013\end{array} \\ \begin{array}{l}V_{85 M C} \text { at the middle horizontal } \\ \text { curve, } \\ \text { horizontal curve radius }(R)\end{array} & \begin{array}{l}\text { Misaghi \& Hassan, } \\ 2005\end{array}\end{array}$

Usually, in the design standards, the minimum radius of the horizontal curve $\left(R_{\min }\right)$ is determined assuming skid resistance factor for a wet and clean surface. Therefore, when measuring driving speed on a dry surface, commonly registered driving speeds are much higher than those assumed for $V_{d}$. Nevertheless, the radius of the horizontal curve in Lithuanian road design guidelines has unreasonably high safety margin compared to other countries. 
Figure 1 and Table 1 present, the average operating speed models Evaluation of Horizontal Curve Radius Effect developed by many authors based on field studies show that drivers tend to drive faster than the $V_{d}$ in the horizontal curve specified in the road design guidelines. This consideration agrees with the findings of OSPMs presented in Table 1.

There is a lack of in-depth investigation that has been reported on the $V_{85}$ model for the horizontal alignment, which reflects rural roads condition in Lithuania. Nether wide range of speed measurements associated with the investigation of road geometry was implemented.

\section{Data collection}

The research program focused on the driving speed in the horizontal curves, which include:

- the selection of road sections appropriates for the study;

- the collection of field data of the road sections;

- the measurement of driving speeds at each section.

Site selection was limited to sections with the following characteristics (Lamm, Beck, Ruscher, Mailänder, Cafiso, \& La Cava, 2007):

- a tangent to the horizontal curve section;

- removed from the influence of intersections;

- without physical features adjacent to or in the roadway, which may create abnormal hazards;

- average annual daily traffic between $1000 \mathrm{vpd}$ and $12000 \mathrm{vpd}$.

Field data collection involves obtaining parameters of each horizontal curve. Information recorded includes a radius of the horizontal curve, length of the horizontal curve, superelevation rate, gradient, lane width and average annual daily traffic.

Speed data collection ensured that the driving speed of all passing vehicles was recorded. The speed of different type of vehicles was

Table 2. Example of data recorded on the road No. 2610, Site 1

\begin{tabular}{ccccc}
\hline Date & Direction & Speed, $\mathrm{km} / \mathrm{h}$ & Length, $\mathrm{dm}$ & Class \\
\hline $\begin{array}{c}15 / 01 / 2020 \text { 09:20 } \\
<\ldots>\end{array}$ & Inner radius lane & 59 & 42 & $\mathrm{PC}$ \\
$\begin{array}{c}15 / 01 / 202009: 22 \\
<\ldots>\end{array}$ & Outer radius lane & 51 & 46 & $\mathrm{PC}$ \\
$\begin{array}{c}15 / 01 / 202009: 26 \\
<\ldots>\end{array}$ & Outer radius lane & 41 & & \\
\hline
\end{tabular}

Note: PC - a passenger car, HV - heavy vehicle. 


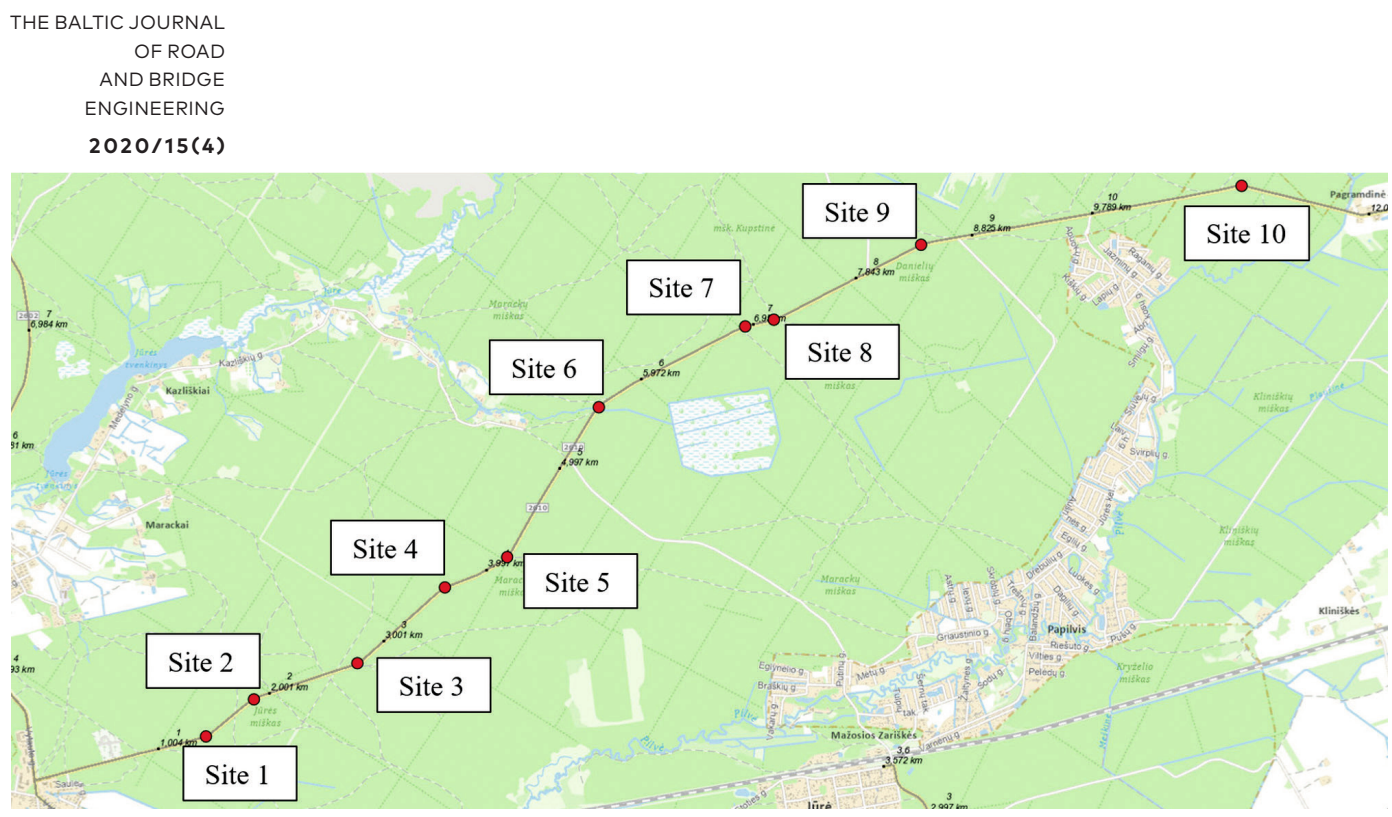

Figure 2. Speed measurements sites along the road No. 2610

collected by observation value using "SDR Traffic Detector". This device records every single vehicle speed, date, time, direction and classifies vehicles in four categories by determining its length. Example of data recorded presented in Table 2. The data collected were recorded to the database to make it easy for further analysis. The observations of speed were recorded at the middle point of the horizontal curve placing detector at outside lane shoulder. The detector, as specified in the installation manual, was faced to upcoming traffic on mounting pole and turned at the angle of $45^{\circ}$ to road axis.

The research was conducted on the selected road No. 2610 Kazlu Rūda-Pažèrai (Figure 2). Speed measurements sites were selected in the middle point of every horizontal curve in $10 \mathrm{~km}$ long road section. The test road was chosen according to the regional significance, pavement type and condition. The asphalt pavement was laid in the different test road sections in 2009-2014. Annual daily traffic is 1196 veh/year, and trucks consist below $15 \%$ of all traffic. Superelevation on the horizontal curves is fixed at $4 \%$, and the longitudinal gradient is less than $4 \%$. Long tangents separate horizontal curves. Spiral horizontal curves are applied at each horizontal curve in both directions. Also, the influence of intersections is insignificant, and the test road is a transit route. Speed measurement device mounted in place on short pole at the height of $1.2 \mathrm{~m}$ (Figure 3). 


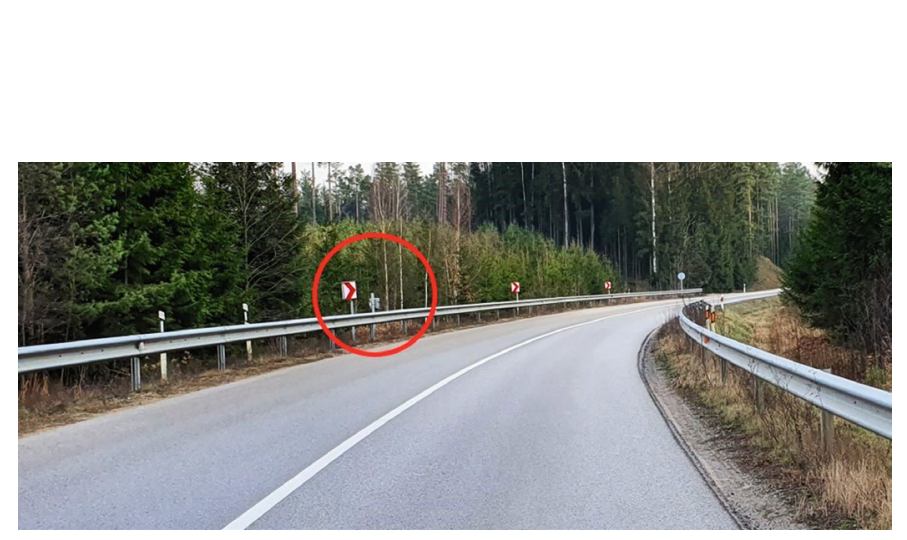

Figure 3. The speed measurement device is mounted in place Site 6 (marked in red circle)

\section{Data analysis}

Driving speed data of each Site was categorised and filtered by its time (day, twilight, and night). In further analysis, only Day time speed data were analysed. The free flow condition is satisfied when the gap between two adjacent vehicles is of $6 \mathrm{~s}$ (Lamm \& Choueiri, 1987). Statistical analysis was carried out to verify the hypothesis of free flow. The data were grouped by the time between vehicles: below $3 \mathrm{~s}$, no less than $3 \mathrm{~s}$ and below $6 \mathrm{~s}$, no less than $6 \mathrm{~s}$, also trucks data were filtered out and excluded. Limitations in the amount of data available for trucks made it more reasonable to analyse with only the passenger car data.

Two statistical tests were performed to evaluate the difference between the mean speeds and the speed variance of isolated and unisolated vehicles. The absence of the significant difference between the mean speeds and the speed variances indicates that these samples can be combined as one sample.

Random independent samples drawn from two populations are used to test the equality of two population means. It is assumed that sufficiently large samples are large enough, e.g. more than 25 observations (Washington, Karlaftis, Mannering, \& Anastasopoulos, 2010). The null hypothesis $H_{0}$ in the two-tailed test states that the two population means $\mu_{1}$ and $\mu_{2}$ are equal. The test statistic is calculated as:

$$
Z=\frac{\left(\bar{X}_{1}-\bar{X}_{2}\right)-\left(\mu_{1}-\mu_{2}\right)}{\sqrt{\frac{s_{1}^{2}}{n_{1}}+\frac{s_{2}^{2}}{n_{2}}}},
$$

where $\mu$ - population mean, $\bar{X}$ - sample average, $s^{2}$ - sample variance, $n$ sample size. 
In Eq. (2) $\left(\mu_{1}-\mu_{2}\right)$ is equal to zero under the null hypothesis, $\left(\bar{X}_{1}-\bar{X}_{2}\right)$ is the actual difference in the sample means, $s_{1}^{2}$ and $s_{2}^{2}$ are the sample variances and $n_{1}$ and $n_{2}$ are the number of observations in the two samples. The denominator in the Eq. (2) is the standard error of the difference between the two sample means and requires two independent samples. The confidence interval for the difference in means is $t$-distributed with degrees of freedom equal to $\left(n_{1}+n_{2}-2\right)$. The null hypothesis is rejected when the calculated test statistic is larger than the critical value obtained from the $t$ distribution tables.

Random independent samples drawn from two populations are used to test the equality of two population variances. The null hypothesis $H_{0}$ in the two-tailed test states that the two variances $\sigma_{1}^{2}$ and $\sigma_{1}^{2}$ are equal. The test statistic is calculated as:

$$
F_{\left(n_{1}-1, n_{2}-1\right)}=\frac{s_{1}^{2}}{s_{2}^{2}}
$$

where $F_{\left(n_{1}-1, n_{2}-1\right)}$ is an $F$-distributed random variable with $n_{1}-1$ degree of freedom in the numerator and $n_{2}-1$ degree of freedom in the denominator.

The larger sample variance is placed in the numerator of the Eq. (3). The null hypothesis is rejected when the calculated test statistic is larger than the critical value obtained from the $F$ distribution tables. Both hypothesis tests were performed with a $95 \%$ confidence level.

\subsection{Example Site 1}

Interest is focused on whether the mean speed difference between unisolated vehicles (time is below $3 \mathrm{~s}$ ) and isolated vehicles (time is no less than $6 \mathrm{~s}$ ) exists. All recorded data was filtered and exclusions of heavy vehicles, night and twilight were eliminated. Were used 46 observations below $3 \mathrm{~s}$ and 445 observations no less than $6 \mathrm{~s}$ to test this hypothesis. A $5 \%$ significance level was used. Descriptive statistics show that average speeds in below $3 \mathrm{~s}$ and no less than $6 \mathrm{~s}$ are $\bar{X}_{\text {below 3 s }}=68.93$ and $\bar{X}_{\text {noless han 6 s }}=69.41$, respectively. Further, it was found that the variances are $s_{\text {below } 3 \mathrm{~s}}^{2}=54.20$ and $s_{\text {no less than } 6 \mathrm{~s}}^{2}=92.44$ respectively. The competing hypothesis was (Eqs (4) and (5):

$$
\begin{aligned}
& H_{0}: \mu_{\text {below } 3 \text { s }}-\mu_{\text {noless than 6s }}=0, \\
& H_{a}: \mu_{\text {below 3s }}-\mu_{\text {noless than 6s }} \neq 0 .
\end{aligned}
$$


Table 3. Descriptive statistics for Site 1 recorded

\begin{tabular}{lcc}
\hline \multirow{2}{*}{$\begin{array}{c}\text { t-test: two-sample assuming } \\
\text { unequal variances }\end{array}$} & Unisolated vehicle & Isolated vehicle \\
\cline { 2 - 3 } Mean & below 3 s & no less than 6 s \\
Variance & 68.93 & 69.41 \\
Observations & 54.20 & 92.44 \\
Hypothesized Mean Difference & 46 & 445 \\
$d f$ & 0.401 & \\
$t$ stat & -0.445 & \\
$P$ (T no less than $t$ ) one-tailed & 1.670 & \\
$t$ critical one-tailed & 0.690 & \\
$P$ (T no less than $t$ ) two-tailed & 1.999 & \\
$t$ critical two-tailed & & \\
\hline
\end{tabular}

Evaluation of Horizontal Curve Radius Effect on Driving Speed in Two Lane Rura Road. Pilot Study

Using Eq. (2), the test statistic is (Eq. (6):

$$
Z=\frac{(68.93-69.41)-0}{\sqrt{\frac{54.20}{46}+\frac{92.44}{445}}}=-0.401 .
$$

The test statistic (Table 3) is lower than 1.999, the critical value for a two-tailed test at the 5\% significance level, and so the null hypothesis is accepted. This result indicates that at Site 1 , there is no mean speed increase or decrease between unisolated vehicles (time is below $3 \mathrm{~s}$ ) and isolated vehicles (time is no less than $6 \mathrm{~s}$ ). Thus, with 95\% confidence, speed means are equal in the interval between $-0.944 \mathrm{~km} / \mathrm{h}$ and $0.000 \mathrm{~km} / \mathrm{h}$.

The mean speeds between isolated and unisolated vehicles in nine sites were found to be equal (Table 4). The result at Site 10 indicates that there is a mean speed increase between unisolated vehicles (time is below $3 \mathrm{~s}$ ) and isolated vehicles (time is no less than $6 \mathrm{~s}$ ). Thus, with 95\% confidence means are not equal between $-5.937 \mathrm{~km} / \mathrm{h}$ and $0.000 \mathrm{~km} / \mathrm{h}$.

The speed variance for isolated and unisolated vehicles in all sites were found to be equal. The result of the higher speed variance for isolated vehicles is reflected in the $V_{85}$, that are slightly higher than for unisolated vehicles (from $0.15 \mathrm{~km} / \mathrm{h}$ to $6.00 \mathrm{~km} / \mathrm{h}$ ). A higher variance for isolated vehicles was obtained due to the presumptive absence of a slower-moving leading vehicle. Following vehicle driver likely more often choose a similar speed to the leading vehicle. The significant difference 
Table 4. Descriptive results of unisolated-isolated vehicles

\begin{tabular}{|c|c|c|c|c|c|c|c|c|c|c|}
\hline \multirow{2}{*}{ Description } & \multicolumn{10}{|c|}{ Site } \\
\hline & 1 & 2 & 3 & 4 & 5 & 6 & 7 & 8 & 9 & 10 \\
\hline $\begin{array}{l}\text { Length of the straight section } \\
\text { before the horizontal curve, } m\end{array}$ & 657 & 343 & 673 & 719 & 398 & 834 & 1086 & 21 & 1067 & 426 \\
\hline Horizontal curve radius, $m$ & 60 & 450 & 250 & 250 & 150 & 300 & 550 & 550 & 500 & 180 \\
\hline Horizontal curve length*, m & 37 & 224 & 168 & 171 & 161 & 228 & 233 & 235 & 225 & 122 \\
\hline $\begin{array}{l}\text { Length of the straight section } \\
\text { after the horizontal curve, m }\end{array}$ & 343 & 673 & 719 & 398 & 834 & 1086 & 21 & 1067 & 426 & 756 \\
\hline $\begin{array}{l}\text { Number of observations, } \\
\text { below } 3 \mathrm{~s}\end{array}$ & 46 & 54 & 58 & 67 & 62 & 71 & 64 & 67 & 52 & 75 \\
\hline $\begin{array}{l}\text { Number of observations, } \\
\text { no less than } 6 \mathrm{~s}\end{array}$ & 445 & 429 & 430 & 453 & 410 & 470 & 481 & 475 & 534 & 529 \\
\hline Equal variance & + & + & + & + & + & + & + & + & + & + \\
\hline Equal $V_{\text {mean }}$ & + & + & + & + & + & + & + & + & + & - \\
\hline$V_{\text {mean }}($ below $3 \mathrm{~s}), \mathrm{km} / \mathrm{h}$ & 68.93 & 78.65 & 78.09 & 79.66 & 72.81 & 81.23 & 86.38 & 84.37 & 82.52 & 72.19 \\
\hline$V_{\text {mean }}($ no less than $6 \mathrm{~s}), \mathrm{km} / \mathrm{h}$ & 69.41 & 80.89 & 78.93 & 81.15 & 74.21 & 82.20 & 88.81 & 86.72 & 85.40 & 75.16 \\
\hline$V_{85}($ below $3 \mathrm{~s}), \mathrm{km} / \mathrm{h}$ & 75.00 & 88.05 & 87.00 & 90.10 & 83.85 & 88.00 & 98.55 & 95.10 & 95.00 & 82.00 \\
\hline$V_{85}($ no less than $6 \mathrm{~s}), \mathrm{km} / \mathrm{h}$ & 79.00 & 93.00 & 90.00 & 92.00 & 84.00 & 94.00 & 103.00 & 99.00 & 100.00 & 86.00 \\
\hline $\begin{array}{l}\text { Difference of } V_{85} \text { (no less } \\
\text { than } 6 \mathrm{~s})-V_{85} \text { (below } 3 \mathrm{~s} \text { ), } \\
\mathrm{km} / \mathrm{h}\end{array}$ & 4.00 & 4.95 & 3.00 & 1.90 & 0.15 & 6.00 & 4.45 & 3.90 & 5.00 & 4.00 \\
\hline Variance (speed, below 3 s) & 54.20 & 124.65 & 80.47 & 95.62 & 96.52 & 110.55 & 189.44 & 113.60 & 155.98 & 88.21 \\
\hline $\begin{array}{l}\text { Variance (speed, no less } \\
\text { than } 6 \mathrm{~s} \text { ) }\end{array}$ & 92.44 & 144.41 & 138.77 & 127.08 & 116.52 & 148.97 & 186.26 & 171.94 & 201.02 & 121.70 \\
\hline
\end{tabular}

Note: $V_{85}$ calculated and grouped by the time gap between vehicles: below $3 \mathrm{~s}$, no less than $6 \mathrm{~s}$, that identifies isolated and unisolated vehicles; * including transitions.

can be observed in mean speeds when analysing more horizontal curves or a particular combination of road alignment elements.

In further analysis, it was used only isolated vehicles data as stated by Lamm, Beck, Ruscher, Mailänder, Cafiso, \& La Cava (2007) to avoid errors in the assessment of $V_{85}$.

Next comparison was between the isolated vehicles $V_{85}$ versus $V_{d}$ and posted speed limit. Descriptive statistics and results presented in Table 5 .

The permissible speed limit in Sites 1 through 10 is no higher than $90 \mathrm{~km} / \mathrm{h}$. The absence of a posted speed limit sign indicates the permissible speed limit is $90 \mathrm{~km} / \mathrm{h}$ as stated in the national regulation. The posted speed limit in all Sites is no lower the $V_{d}$ (Table 5). 
Table 5. Descriptive results for unisolated vehicles in all Sites recorded

\begin{tabular}{|c|c|c|c|c|c|c|c|c|c|c|}
\hline Radius, m & 60 & 450 & 250 & 250 & 150 & 300 & 550 & 550 & 500 & 180 \\
\hline Site & 1 & 2 & 3 & 4 & 5 & 6 & 7 & 8 & 9 & 10 \\
\hline Average & 69.4 & 83.1 & 78.9 & 81.2 & 74.2 & 82.2 & 88.8 & 86.7 & 85.4 & 75.2 \\
\hline $\begin{array}{l}\text { Standard } \\
\text { deviation }\end{array}$ & 9.60 & 9.84 & 11.77 & 11.26 & 10.78 & 12.19 & 13.63 & 13.10 & 14.16 & 11.02 \\
\hline Variance & 92.4 & 97.0 & 138.8 & 127.1 & 116.5 & 149.0 & 186.3 & 171.9 & 201.0 & 121.7 \\
\hline Min & 26 & 32 & 29 & 31 & 13 & 28 & 44 & 48 & 34 & 43 \\
\hline Max & 102 & 113 & 116 & 127 & 103 & 116 & 131 & 125 & 127 & 105 \\
\hline Count & 445 & 429 & 430 & 453 & 410 & 470 & 481 & 475 & 534 & 529 \\
\hline$V_{85}$ & 79.00 & 93.00 & 90.00 & 92.00 & 84.00 & 94.00 & 103.00 & 99.00 & 100.00 & 86.00 \\
\hline $\begin{array}{l}\text { Posted speed } \\
\text { limit, km/h }\end{array}$ & 70 & 90 & 90 & 90 & 70 & 70 & 90 & 90 & 70 & 50 \\
\hline $\begin{array}{l}\text { Overspeeding } \\
\text { posted speed, } \\
\%\end{array}$ & $50 \%$ & $24 \%$ & $17 \%$ & $21 \%$ & $71 \%$ & $88 \%$ & $44 \%$ & $41 \%$ & $37 \%$ & $98 \%$ \\
\hline$V_{d}, \mathrm{~km} / \mathrm{h}$ & 30 & 80 & 70 & 70 & 50 & 70 & 90 & 90 & 85 & 60 \\
\hline $\begin{array}{l}\text { Overspeeding } \\
V_{d} \%\end{array}$ & $100 \%$ & $62 \%$ & $81 \%$ & $87 \%$ & $98 \%$ & $88 \%$ & $63 \%$ & $41 \%$ & $53 \%$ & $91 \%$ \\
\hline
\end{tabular}

It was determined that from $17 \%$ to $98 \%$ of drivers tend to exceed posted speed limit, and from $41 \%$ to $100 \%$ of drivers exceeds $V_{d}$ in the horizontal curve.

The results indicate that there is a substantial inconsistency between Lithuanian road design guideline and permissible speed to how the driver recognises road geometry and what driving speed is expected from the horizontal alignment element. The radius of the horizontal curve posted speed limit, and permissible speed is few of many or indecisive factor on the driver decision of driving speed.

There is stated target in Lithuanian State Traffic Safety Improvement Program "Vision - Zero": reduce the proportion of motor vehicles exceeding the permissible speed on rural roads, from $68 \%$ in the year 2017 till 20\% in the year 2030 (The Ministry of Transport..., 2019). The initial results of the Pilot Study conducted indicate that the levels of overspeeding are generally far from the 2030 targets. The statement holds even the level of $V_{85}$ somewhat overestimated and the speed compliance underestimated considered the measurements made on a single straight flat road, absence of major intersections or driving speed limiting environment. 


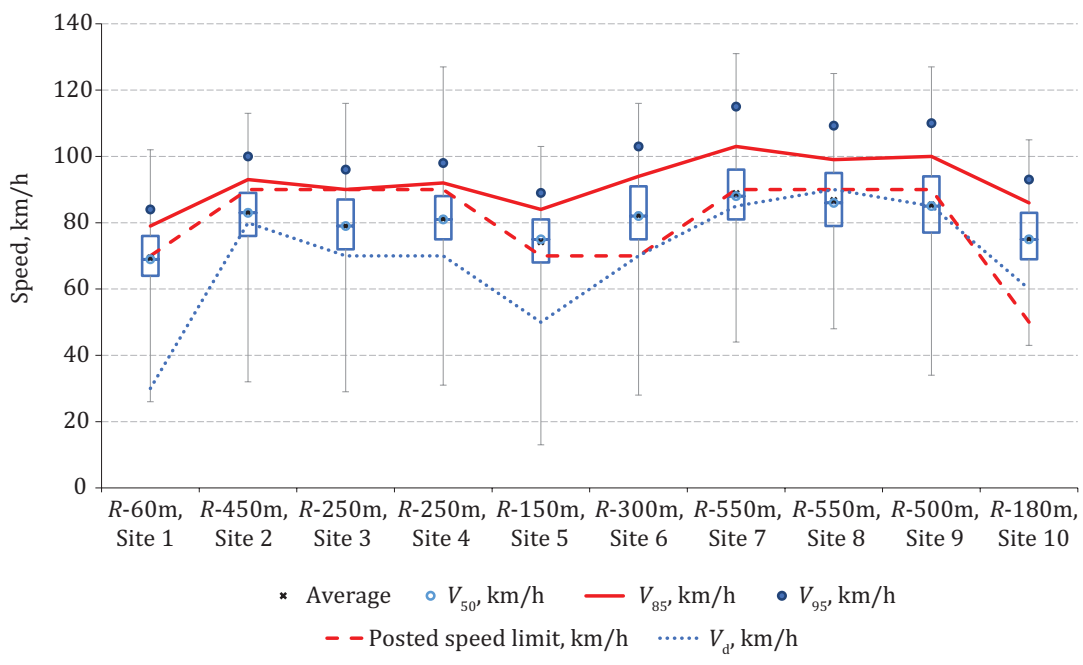

Figure 4. Road No. 2610 speed profile with measured driving speed and calculated $V_{50}, V_{85}, V_{95}$ and $V_{d}$

In Figure 4 presented speed profile and basic statistics of road section analysed. Posted speed limit, $V_{d}$ and calculated $V_{85}$ shows overspeeding tendency along the road section. Also, for speed distribution overview percentile of $V_{50}$ and $V_{95}$ is marked.

In Site 2, Site 3, and Site 4 there is no posted speed limit, and $V_{85}$ is from $0 \mathrm{~km} / \mathrm{h}$ to $4 \mathrm{~km} / \mathrm{h}$ higher than permissible speed and $13-24 \mathrm{~km} / \mathrm{h}$ higher than $V_{d}$ (Figure 4). In Site 6 radius of the horizontal curve is $300 \mathrm{~m}$, but despite posted speed limit is $70 \mathrm{~km} / \mathrm{h}$, drivers tend to choose their driving speed such as in the horizontal curves with radius 250$450 \mathrm{~m}$ (Site 2, Site 3, and Site 4).

In all sites, $V_{d}$ as stated in Lithuanian technical regulation is 13-49 km/h lower than actual measured $V_{85}$.

The posted speed limit, in most cases, differs from $V_{d}$. The presumed reason is the road environment parameters or local approach. In all cases, the posted speed limit is a safe driving speed, which should be lower the $V_{d}$.

In Figure 5 presented measured $V_{85}, V_{d}$ and posted speed limit by radius increase order. Calculated $V_{85}$ shows an overspeeding downward trend with an increase of radius compared to $V_{d}$. Despite permissible speed limit variates from $50 \mathrm{~km} / \mathrm{h}$ to $90 \mathrm{~km} / \mathrm{h}$ and $V_{d}$ from $30 \mathrm{~km} / \mathrm{h}$ to $90 \mathrm{~km} / \mathrm{h}, V_{85}$ remains from $79 \mathrm{~km} / \mathrm{h}$ to $103 \mathrm{~km} / \mathrm{h}$.

Also, the tendency found that in an increase of $R$, the measured $V_{85}$ variates less between sites with a radius above $250 \mathrm{~m}$ (Figure 5). 


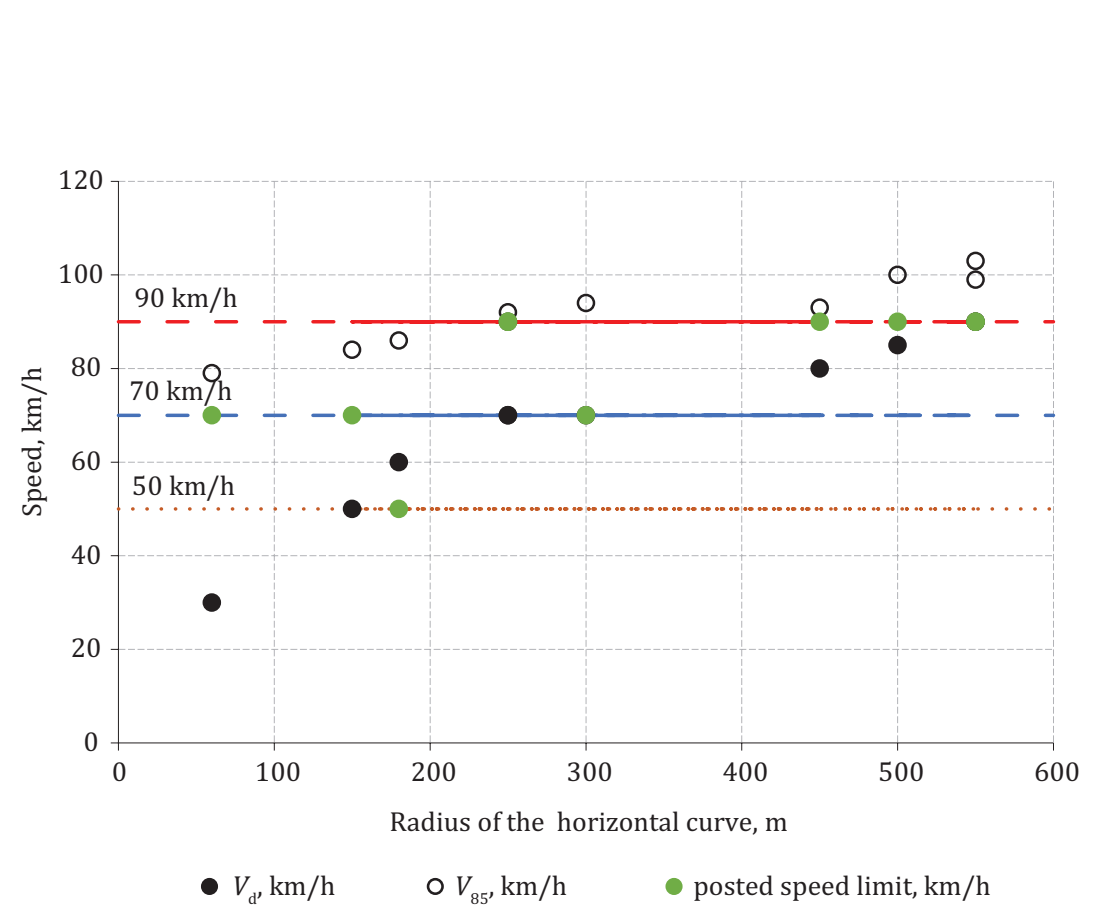

Figure 5. Measured $V_{85}, V_{d}$ and posted speed limit in comparison to various radius of horizontal curve

Measured and calculated $V_{85}$ values are above line $90 \mathrm{~km} / \mathrm{h}$. The choice of driving speed becomes similar to the desired driving speed, that is $90-103 \mathrm{~km} / \mathrm{h}$ and corresponds to OSPM developed by CamachoTorregrosa, Pérez-Zuriaga, Campoy-Ungría, \& García-García (2013) and Castro, Pardillo-Mayora, \& Jurado (2013). Drivers were found to reduce speed for the horizontal curve with the posted speed limit, but the magnitude is much less than the suggested speed reduction on the road sign, which corresponds to research done by Wang, Hallmark, Savolainen, \& Dong (2018).

Calculated $V_{85}$ values (Figure 5) on individual horizontal curves correspond to the OSPM presented in Table 1 and are more like regulation of various countries road design guidelines, than to Lithuanian road design guidelines (Figure 1).

\section{Conclusions}

1. This paper shows the results of a pilot study on the relationship between design speed on an individual horizontal curve and measured operating speed towards posted speed limit and credible speed limit. Conclusions for the horizontal curves on 
specific road analysed must be approved with additional research before adoption to the entire road network.

2. It was determined limitation differences in radius of the horizontal curve dependent on country and regulation. Differences exponentially depend on speed and at $30 \mathrm{~km} / \mathrm{h}$, radius of the horizontal curve difference is only $28 \mathrm{~m}$, at $50 \mathrm{~km} / \mathrm{h}-90 \mathrm{~m}$, at $70 \mathrm{~km} / \mathrm{h}-170 \mathrm{~m}$, at $90 \mathrm{~km} / \mathrm{h}-300 \mathrm{~m}$.

3. The operating speed data, obtained during the study on individual curves, coincide more to design speed in different countries than stated in Lithuanian regulation.

4. The literature review shows that the radius of the horizontal curve has a little effect on the speed choice of drivers. Design speed in Lithuania is one of the lowest among many countries reviewed for the respective radius of the horizontal curve. Widely used and confirmed in multiple Operating Speed Prediction Models, minimum radius of the horizontal curve for specific design speed in road analysed is much lower than accepted in Lithuanian road design guidelines. The critical finding is that despite differences that exist between operating speed and design speed there is a still seen tendency: when the radius of the horizontal curve increases, the difference between operating speed and design speed decrease.

5. It was determined that drivers choose a driving speed higher than permissible speed or as intended by the designer using the geometrical parameters specified in the road design guidelines. The research shows that from $17 \%$ to $98 \%$ of drivers tend to exceed posted speed limit, and from $41 \%$ to $100 \%$ of drivers exceeds design speed in horizontal curve. Thus, the radius of horizontal curves specified in the road design guidelines for a given speed differs from the driving speed chosen by the drivers. Design inconsistencies appear when the permitted speed of one element of the road alignment coincides with higher design speed (like operating speed, usually $90 \mathrm{~km} / \mathrm{h}$ ) and the other element with lower design speed (when design speed is below $90 \mathrm{~km} / \mathrm{h}$, usually operating speed is much higher). Such design inconsistencies reduce recognizability of the road environment and increase the probability of overspeeding.

6. Change in speed limit is often subject to intense social and political debates. A credible speed limit on horizontal curve, with a specific radius, is a limit that is logical by (the majority of) drivers for that specific road in the particular road environment.

7. The horizontal curves of the radius more than $250 \mathrm{~m}$ and the absence of additional safety measures have no driving speed 
limitation effect on a choice for driving speed when design speed is $90 \mathrm{~km} / \mathrm{h}$. Before deciding on the increase of speed limit in such horizontal curves, road environment and accident data at a specific location must be considered with great care.
Evaluation of Horizontal Curve Radius Effect on Driving Speed in Two Lane Rural Road. Pilot Study

\section{REFERENCES}

Aarts, L., van Nes, N., Donkers, E., \& van der Heijden, D. (2010). Towards safe speeds and credible speed limits. In 4th International Symposium on Highway Geometric Design, Polytechnic University of Valencia, Transportation Research Board.

American Association of State Highway Transportation Officials (AASHTO) (2018). A Policy on Geometric Design of Highways and Streets 2018 (7th).

Abbas, S. K. S., Adnan, M. A., \& Endut, I. R. (2011). Exploration of $85^{\text {th }}$ percentile operating speed model on horizontal curve: a case study for two-lane rural highways. Procedia - Social \& Behavioral Sciences, 16, 352-363. https://doi.org/10.1016/j.sbspro.2011.04.456

Camacho-Torregrosa, F. J., Pérez-Zuriaga, A. M., Campoy-Ungría, J. M., \& García-García, A. (2013). New geometric design consistency model based on operating speed profiles for road safety evaluation. Accident Analysis \& Prevention, 61, 33-42. https://doi.org/10.1016/j.aap.2012.10.001

Castro, M., Pardillo-Mayora, J. M., \& Jurado, R. (2013). Development of a local operating speed model for consistency analysis integrating laser, GPS and GIS for measuring vehicles speed. The Baltic Journal of Road and Bridge Engineering, 8(4), 281-281. https://doi.org/10.3846/bjrbe.2013.36

DHV Environment and Transportation (2005). Sustainable safe road design: a practical manual. September, 218.

Dilling, J. (1973). Fahrverhalten von Kraftfahrzeugen auf kurvigen Strecken. Research Report. In Strassenbau und Strassenverkehrstechnik. Bonn-Bad Godesberg, Germany. (in German)

Elliott, M., Dawson, R. \& Edwards, J. (2006). Towards real process improvement from internal auditing - a case study. Software Quality Journal 14, 53-64. https://doi.org/10.1007/s11219-006-6001-3

Elvik, R. (2014). Fart og trafikksikkerhet: nye modeller. TØI Transportøkonomisk institutt. (in Swedish)

European Commission (2015). Speed and Speed Management 2015. In European Commission, Directorate General for Transport.

European Conference of Ministers of Transport, \& OECD/ECMT Transport Research Centre. (2006). Speed management. In OECD/ECMT Transport Research Centre (Vol. 4).

Gintalas, V. (2010). Possibilities for the improvement of the quality of design solutions in the gravel road reconstruction projects. The Baltic Journal of Road and Bridge Engineering, 5(3), 177-184.

https://doi.org/10.3846/bjrbe.2010.25 
Goldenbeld, C., \& van Schagen, I. (2007). The credibility of speed limits on $80 \mathrm{~km} / \mathrm{h}$ rural roads: The effects of road and person (ality) characteristics. Accident Analysis \& Prevention, 39(6), 1121-1130. https://doi.org/10.1016/j.aap.2007.02.012

Kanellaidis, G., Golias, J., \& Efstathiadis, S. (1990). Drivers' speed behaviour on rural road curves. Traffic Engineering and Control, 31(7-8), 414-415.

Lamm, R., Beck, A., Ruscher, T., Mailänder, T., Cafiso, S., \& La Cava, G. (2007). How to make two-lane rural roads safer: scientific background and guide for practical application. Southampton, UK; Boston, MA: WIT Press.

Lamm, R., \& Choueiri, E. M. (1987). Recommendations for evaluating horizontal design consistency based on investigations in the state of New York. Transportation Research Record, 1122, 68-78.

Lamm, R., Psarianos, B., \& Mailaender, T. (1999). Highway design and traffic safety engineering handbook.

Misaghi, P., \& Hassan, Y. (2005). Modeling operating speed and speed differential on two-lane rural roads. Journal of Transportation Engineering, 131(6), 408-418. https://doi.org/10.1061/(ASCE)0733-947X(2005)131:6(408)

The Ministry of Transport and Communications of the Republic of Lithuania (2019). State traffic safety improvement program "Vision - Zero", Resolution of the Government of the Republic of Lithuania, Reg. No. 19-3, 32. (in Lithuanian)

Srinivasan, R., Parker, M., Harkey, D., Tharpe, D., \& Sumner, R. (2006). Expert system for recommending speed limits in speed zones. National Cooperative Highway Research Program, Transportation Research Board, National Research Council. Project No. 3-67.

SWOV (2013). Sustainable safety: principles, misconceptions, and relations with other visions. July, 1-6.

Vadeby, A., \& Forsman, Å. (2014). Evaluation of new speed limits in Sweden: A sample survey. Traffic Injury Prevention, 15(8), 778-785. https://doi.org/10.1080/15389588.2014.885650

Wang, B., Hallmark, S., Savolainen, P., \& Dong, J. (2018). Examining vehicle operating speeds on rural two-lane curves using naturalistic driving data. Accident Analysis \& Prevention, 118, 236-243. https://doi.org/10.1016/j.aap.2018.03.017

Washington, S., Karlaftis, M. G., Mannering, F., \& Anastasopoulos, P. (2020). Statistical and econometric methods for transportation data analysis. CRC press. https://doi.org/10.1201/9780429244018

World Health Organization (2018). Global Status Report on Road Safety 2018. 